\title{
AБOHEHTCKOE ОБОРУДОВАНИЕ
}

\section{АУДИО-КОНФЕРЕНЦ- ТЕЛЕФОН Yealink CP920}

Ю.Якушин, "АйПиМатика"

DOI: 10.22184/2070-8963.2017.69.8.62.63

Компания "АйПиМатика" представляет новый аудио-конференц-телефон Yealink CР920.

В прошлом номере журнала "ПЕРВАЯ МИЛЯ" компания "АйПиматика" ознакомила читателей с новым аудиоконференц-телефоном с поддержкой SIP-Yealink CP960. Но прошло совсем немного времени, и вот уже осенью 2017 года компания Yealink выпустила более бюджетный аудио-конференц-телефон - Yealink CP920.

Чемжеразличаютсяэтидве модели? Внешнеони очень похожи: новый телефон имеет такой же форм-фактор, как и его "старший брат" Yealink CP960 - Y-образную форму. Однако, в отличие от других аудио-конференцтелефонов Yealink, новая модель не поддерживает работу с внешними микрофонами. Таким образом, Yealink CР920 - это конференц-телефон корпоративного уровня для переговорных комнат малого и среднего размера. При этом устройство устанавливает новые стандарты качества звука и погружает участников конференции в обсуждение без отвлечения на внешние раздражители, обеспечивая оптимальный баланс между простотой использования и богатым функционалом. Кроме того, устройство получило новую клавиатуру - теперь это сенсорные кнопки (на корпусе

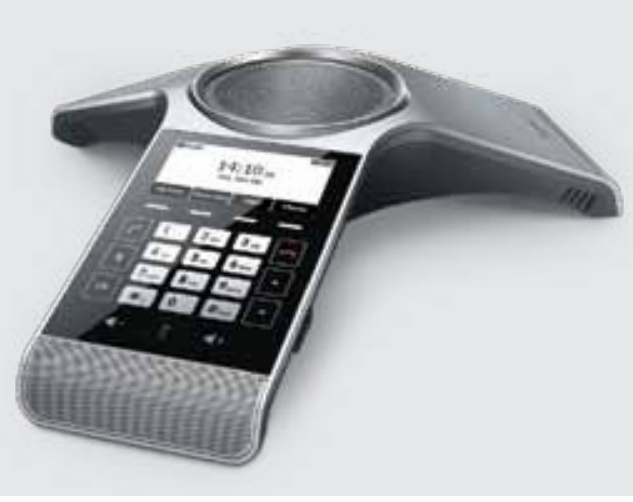

вынесены сенсорные кнопки отключения микрофона с двухцветной световой индикацией).

К функциям нового СР920 относятся: SIP-аккаунт; удержание, отключение микрофона, DND ("не беспокоить"); запись разговоров на внутреннюю память телефона и на USB-телефон; горячая линия; 5-сторонняя конференция; повторный набор номера, режим ожидания, экстренные вызовы; переадресация вызова, трансфер вызова, правила набора; выбор мелодии/загрузка/ удаление; горячая линия, экстренные вызовы; ручная/ автоматическая установка времени; регулировка громкости; сопряжение через Bluetooth 4.0 для подключения в конференцию мобильного телефона.

Основные характеристики этого

аудиоконференц-телефона:

- звук формата Optima HD;

- технология шумоподавления Yealink;

- рабочая дистанция захвата голоса шесть метров с зоной покрытия $360^{\circ}$;

- три встроенных микрофона;

- кодеки: G.722.1C, G.722, G.711(A/u), G.729AB, G.726, G.723, iLBC, Opus;

- DTMF: In-band, Out-of-band (RFC 2833) и SIP INFO;

- Full-duplex (полнодуплексная) громкая связь с АЕС (подавление эха);

- VAD (обнаружение активности голоса), CNG (генератор комфортного шума), PLC (маркирование потери пакета с медиа-данными), АЈВ (адаптивный буфер для голосовых пакетов), AGC (автоматическая регулировка чувствительности микрофона);

- графический 3.1" экран с разрешением 248×120 с подсветкой;

- поддержка Power over Ethernet;

- встроенный Wi-Fi (2,4 ГГц, 802.11 b/g/n) для подключения в сеть организации; 
Таблица. Сравнительные характеристики новых аудио-конференц-телефонов Yealink

\begin{tabular}{|c|c|c|c|c|}
\hline \multicolumn{2}{|r|}{ Модель } & CP960 & CP920 & CP860 \\
\hline \multirow{3}{*}{ Основные } & Операционная система & Android 5.1 .1 & Linux & Linux \\
\hline & Bluetooth & Bluetooth 4.0 & Bluetooth 4.0 & $x$ \\
\hline & Wi-Fi & $802.11 \mathrm{a} / \mathrm{b} / \mathrm{g} / \mathrm{n} / \mathrm{ac}$ & $802.11 \mathrm{~b} / \mathrm{g} / \mathrm{n}$ & $x$ \\
\hline \multirow{2}{*}{ Экран } & Тип & Сенсорный 5" & Графический 3.1" & Графический 2.7" \\
\hline & Разрешение & $720 \times 1080$ & $248 \times 120$ & $192 \times 64$ \\
\hline \multirow{3}{*}{ Голос } & Широкополосные кодеки & G.722, G.722.1C, Opus & G.722, G.722.1C, Opus & G.722 \\
\hline & Узкополосные кодеки & $\begin{array}{c}\text { G.711u/a, G.726, } \\
\text { G.729AB, G.723, iLBC }\end{array}$ & $\begin{array}{c}\text { G.71lu/a, G.726, } \\
\text { G.729AB, G.723, iLBC }\end{array}$ & G.711u/a, G.729AB, iLBC \\
\hline & Зона покрытия & $6 \mathrm{M}$ & $6 \mathrm{M}$ & $3 \mathrm{M}$ \\
\hline \multirow{5}{*}{ Порты } & USB-порт (2.0) & 2 & 1 & 1 \\
\hline & Micro USB-порт & 1 & $x$ & $x$ \\
\hline & Проводные микрофоны (RJ9) & 2 & $x$ & 2 \\
\hline & Беспроводные микрофоны & 2 & $x$ & $x$ \\
\hline & 3,5 мм Jack & 1 & $x$ & 1 \\
\hline \multirow{3}{*}{ Функции } & Технология Yealink Noise Proof & $\checkmark$ & $\checkmark$ & $x$ \\
\hline & $\begin{array}{l}\text { Создание мгновенных } \\
\text { конференций }\end{array}$ & $\checkmark$ & $x$ & $x$ \\
\hline & Отображение говорящего & $\checkmark$ & $x$ & $x$ \\
\hline
\end{tabular}

- поддержка аксессуара Yealink CPN10 для подключения аналоговой телефонной линии.

Следует отметить, в линейке аудио-конференц-телефонов Yealink - три модели: СР960, СР920 и СР860.
Представленная таблица позволяет сравнить некоторые показатели этих устройств.

Более подробную информацию всегда можно попучить на сайте www.ipmatika.ru. 